\title{
Numerical Analysis of Breast Cancer Cell with Gold Nanoparticles Necrosis by Laser Hyperthermia
}

\author{
Shna A. Karim*, Yousif M. Hassan \\ Department of Physics, College of Science, Salahaddin University, Erbil, Kurdistan Region, Iraq
}

\section{${ }^{*}$ Corresponding author: \\ Shna A. Karim, Department \\ of Physics, College of \\ Science, Salahaddin \\ University, Erbil, Kurdistan \\ Region, Iraq \\ E-mail: shna.karim@su.edu. krd}

Received: 15 March 2020

Accepted: 18 May 2020

Published: 30 December 2020

DOI

10.25156/pti.v10n2y2020.pp138-144

\section{A B S T R A C T}

Laser hyperthermia treatment of cancer tissue is widely used in cancer treatment to destroy cancer cells. This study focus on the mechanisms of heat transfer in biological tissues to minimize damage to the tissues resulting from extra heat applied. The important feature of this method is heating of specific region to raise its temperature to a threshold temperature and destroying cancer cells without to destroy surrounding tissue. In this study, we have used the combinations of laser light and gold nanoparticles to investigate the influence of nanoparticles on the spatial distribution of temperature in the tumor and healthy tissues. Accurate simulations and solving Penne's bio-heat transfer equation were used to solve and model the thermal tumor breast cancer in the presence of gold. Nanoparticles of some particular sizes and concentrations were selected. We would like here to stress that our attempt was a theoretical and computer model with some real and hypothesized parameters and homogeneous target. The results of this study help the doctors in the study for results of hyperthermia treatment before using it on the vivo by known the properties of the laser used and the properties of the breast tumor trying to reduce the damage of the treatment.

Keywords: Breast tumor; Gold nanoparticles; Hyperthermia; Penne's equation; Temperature

\section{INTRODUCTION}

Nowadays, nanotechnology is one of the most modern fields of science. Nanotechnology refers to work at scale of 1-100 nm levels. (Hu et al., 2007). Furthermore, LASER, despite its history, over all worldwide is recognized as a modern technology, both of them, with their specific characteristics, have played a major role in modern medicine such as diagnosis and treatment of cancer, with new technologies the new methods have been introduced in medical science, such as treatments using nanoparticles or combinations of lasers and nanoparticles in the treatment (Abou Neel et al., 2015). This new method dose not depends on the availability of oxygen in tumors such as in methods like photodynamic therapy, there is such a limitation and they can be used as alternative methods (Lee et al., 2014).

In the field of cancer treatment gold nanoparticles (AuNPs) and near infra-red (NIR) lasers have attracted great attentions in the past two decades. That is because, AuNPs can excite by NIR, which makes them to be the next generation contrast agents for diagnostic and phototherapeutic applications, other factors such as nanoparticle surface characteristics (Schena et al., 2017), (Raji et al., 2011).
In human bodies, heat transfer is an essential and fundamental process, especially to maintain an almost constant temperature. In fact, in calculations of temperature rise and heat transfer in perfused media interesting results have been obtained in the past several decades, such as, in 1948, Penne's proposed the first constitutive relationship between temperature and the heat exchange between blood flow and solid tissues. The relation is popularly known as penne's linear bio-heat equation, many researchers used it and deal with various problems (Pennes, 1948), (Dahariya and Betz, 2019).

The purpose of this paper is to treat breast cancer using laser as the source of heat, small breast cancer including the AuNPs surrounded by extended health tissue as a solid sphere and investigated the effect of heat and induced heat produced from the AuNPs on the temperature distribution. The modeling of bio-heat transfer and heat induced was useful for the development of biomedical technologies, such as thermotherapy or cooling (Arora et al., 2002).

An ideal therapy assumes that the anticancer agent only destroys the tumor cells. A recent trend in heat therapy is the application of AuNPs on tumors because since heat helps the body treats cancers (Tung et al., 2009). 
An ideal therapy suppose that the anticancer agent for normal tissue to remain unaffected only destroys the tumor cells, cumulative toxicity in healthy tissue cannot be eschewed. To minimize this negative symptom new methods have been discovered like a method allows delivering anticancer agents directly to tumors and target treatments to individual cancer cells. Cancer cells show signs of apoptosis when they are exposed to temperatures that reach $41-47^{\circ} \mathrm{C}$; cell proteins are denatured for temperatures above $50^{\circ} \mathrm{C}$ (Peng and Liang, 2019).

This fact is put into practice in hyper thermal therapy using light-absorbing nanoparticles preferentially localized inside the tumor. There have been many in vivo proofing of the use of nanoparticles in hyper thermal therapy leading to promising results. It has shown that the average volume of tumor in mice decreases after tumor injected by gold nano rods and exposed to laser light in the wave length range near-infrared light (Hirsch et al., 2003), (Collins et al., 2014).

\section{THEORY}

\section{Photothermal Phenomenon}

The photothermal phenomenon can be regarded as internal heat generation in terms of heat transfer because of the laser's photothermal induced. It is expressed as a heat source induced by the laser, as shown in the following equation (Kim et al., 2019).

$$
\mathrm{Q} 1=\mu_{\mathrm{a}}\left(\frac{\mathrm{p}_{1}}{\pi_{\mathrm{r}_{1}}}\right) * \exp \left[-\left(\mu_{\mathrm{a}}+\mu_{\mathrm{s}}\right) * \mathrm{Z} *\left(\frac{\mathrm{r}}{\mathrm{r}_{1}}\right)^{2}\right]
$$

Where $\mu_{\mathrm{a}},(1 / \mathrm{m})$ represents the absorption coefficient and $\mu_{\mathrm{s}},(1 / \mathrm{m})$ reduced scattering coefficient of the tissue; and $\mathrm{p}_{1}$ is the power of the laser; $r_{1}$ is the beam radius of the laser. $r$ is the radius of tumor, $\mathrm{z}$ is the distance from laser source to the target or the center of the sample. When the wavelength of the laser used for irradiation is varied the light absorption coefficient of the medium varies with respect to it, as per Equation (1), if the absorption cofficient $\left(\mu_{a}\right)$ of the medium is low, the energy of the laser cannot be absorbed even if the laser output is large (Kim et al., 2019).

High absorption of the light source by tissue compositions such as melanin and hemoglobin in the visible region, and water increasing absorption by compositions in the infrared region while providing a wavelength window around 650-1100 nm, referred as NIR. The minimum interaction by the biological absorbers therapeutic window minimal interaction by the biological absorbers allows for deeper penetration of the light into the tumor (Manuchehrabadi and Zhu, 2017).

If the tumor is heated in the temperature range of $40-50^{\circ} \mathrm{C}$, this range of temperature is hyperthermia in cancer therapy. It has been demonstrated that cancer cells within the tumor are more vulnerable to heat than healthy cells. Except for the spherical AuNPs, the other types of AuNPs are tuned absorption to the NIR region, making them well-suited for photothermal therapy (Manuchehrabadi and Zhu, 2017), (Dykman and Khlebtsov, 2011), (Kim et al., 2019).

Nanoparticles in a tumor allow for a controlled distribution of heat within a target tumor avoiding damage to surrounding healthy tissues. When AuNPs are excited at their plasmatic frequency by NIR photons, electrons of their metallic surface oscillate collectively. Then, this effect induces a strong absorption of the incident light this phenomenon called Surface Plasmon Resonance (Kim et al., 2019).

\section{Heat Generated by AuNPs}

Photothermal therapy of cancer is the example of AuNP heating by laser, in this application AuNPs inserted in the tumor. The absorption coefficient of the metal nanoparticle is larger than tumor tissue significantly by increasing the absorption of laser energy leading to heating the tumor. Mainly, their review focuses on the biological and thermo physical media responses heated by laser activated AuNPs. Actually, under laser light, there is a bigger number of Aggregation of AuNPs and each of them generates a certain amount of heat, the increase in temperature is due to the heat contributed by $\mathrm{N}$ (number of $\mathrm{NPs} / \mathrm{m}^{3}$ ) of nanoparticles. The heat generated $\mathrm{Q}_{\text {heat }},\left(\mathrm{W} / \mathrm{m}^{3}\right)$ is the sum of heat generated by all NPs, it can be written as the product of $\mathrm{N}$ number of NPs by laser fluence $\mathrm{I}\left(\mathrm{W} / \mathrm{m}^{2}\right)$ and absorption cross-section area $\mathrm{C}_{\text {abs }},\left(\mathrm{m}^{2}\right)$. Laser irradiation of AuNPs inside the tumor and under resonance conditions is the property of nanoparticle through $\mathrm{C}_{\text {abs }}$ which is depends on the falling wavelength; its value can be greater than the actual cross-section of AuNPs due to surface plasmon resonance. The heat generation due to whole AuNPs is (Qin and Bischof, 2012):

$$
\begin{gathered}
\mathrm{Q}_{\text {heat }}=\mathrm{N} * \mathrm{Q}_{\text {nano }}=\mathrm{N} * \mathrm{C}_{\mathrm{abs}} * \mathrm{I}=\mu_{\mathrm{a}} * \mathrm{I} \\
\mu_{\mathrm{a}}=\mathrm{N} * \mathrm{C}_{\mathrm{abs}}
\end{gathered}
$$

The equation (2) contains essential terms requisite for heat generation by laser with AuNPs in tissue. First, absorption cross-section area, which represent the optical properties of AuNPs need to know the shape of nanoparticle, which it can get absorption cross-section area by complicated experimental and theoretical exercise. Second, to determine 
the heat generated and overall tissue optical properties needs to know the distribution of AuNPs and (N) the number of particles third, to estimate thermal response of biological tissue and the heat generation, it needs to know the laser flounce $\mathrm{I}\left(\mathrm{W} / \mathrm{m}^{2}\right)$, which is a function of laser and properties of tissue with AuNPs. Same optical property of AuNP according to their shape is represented in Table 1 (Qin and Bischof, 2012).

\section{Penne's Bio-Heat Equation with Nanoparticles}

Heat can be transferred in tissue by three fundamental ways which are conduction, convection, and radiation, according to fundamental laws of thermodynamics that heat flows from hotter parts in the medium to cooler medium. Radiation part is small significance in biological tissue it can be neglected. (Axelsson, 1999) Photothermal therapy contains internal heat generation and heat transfer in tissues. This is representing by the Penne bio-heat governing equation (Niemz, 1996).

Penne in 1948 developed a model describes the heat transfer in biological tissue well-known Penne's bio-heat transfer equation, conduction, convection $Q_{b}$ is the most important mechanism for thermal energy transfer between tissue and blood flow, which they are the base in the bioheat transfer equation and the internal heat generation is also includes heat generated by metabolism $\left(\mathrm{Q}_{\mathrm{m}}\right)$, and heat generated by the photothermal effect $\left(Q_{1}\right)$. This all is represented in Equation (4) (Axelsson, 1999), (Zhang, 2015), (Kim et al., 2019):

$$
\begin{gathered}
\mathrm{k} \nabla^{2} \mathrm{~T}+\mathrm{Q}_{\mathrm{b}}+\mathrm{Q}_{\mathrm{mt}}+\mathrm{Q}_{1}=\rho \mathrm{c} \frac{\partial \mathrm{T}}{\partial t} \\
\mathrm{k} \nabla^{2} \mathrm{~T}+\rho_{\mathrm{b}} \omega_{\mathrm{b}} \mathrm{c}_{\mathrm{b}}\left(\mathrm{T}_{\mathrm{b}}-\mathrm{T}\right)+\mathrm{Q}_{\mathrm{mt}}+\mathrm{Q}_{1}=\rho \mathrm{c} \frac{\partial \mathrm{T}}{\partial \mathrm{t}}
\end{gathered}
$$

Where $\rho c \frac{\partial T}{\partial t}$ on the right side of the equation shows a shift in the rate of temperature, The $1^{\text {st }}$ term from the left shows heat conduction within the tissue that the temperature gradient causes, the $2^{\text {nd }}$ one represents the transfer of heat between the microcirculatory blood perfusion and the tissue, while the $3^{\text {rd }}$ and the last ones describes the internal generation of heat resulting from outer sources of heat and tissue metabolism,

\begin{tabular}{|c|c|c|c|c|}
\hline Particle & SPR (nm) & Size $(\mathrm{nm})$ & $C_{a b s}\left(n m^{2}\right)$ & Sketch \\
\hline $\begin{array}{l}\text { Spherical } \\
\text { AuNP }\end{array}$ & 528 & $r=20$ & 2827 & \\
\hline Rod AuNP & 797 & $L_{1}=13, L_{2}=49$ & 5674 & \\
\hline
\end{tabular}
where $\rho$ represented the mass density of the breast tissue, $\mathrm{c}$ is the specific heat. $\mathrm{T}$ represents the temperature in $(\mathrm{K})$ and $t$ represents the time in (s). $\nabla^{2}$ represents the Laplacian operator, represents the thermal conductivity, $\rho_{b} c_{b}$ and $\omega_{b}$ are, respectively, density, specific heat, and perfusion rate of blood, $\mathrm{T}_{\mathrm{b}}$ is the temperature of arterial blood, $\mathrm{Q}_{\mathrm{mt}}$ and $\mathrm{Q}_{1}$ are, respectively, $\mathrm{Q}_{\mathrm{mt}}$ is the rate of metabolic heat generation per unit volume of tissue. Moreover, heat deposition in tissues caused by outer heating factors such as laser (Axelsson, 1999), (Zhang, 2015), (Kim et al., 2019).

When the laser beam hits the tumor, which is injected by the nanoparticles, the laser energy is partially absorbed, scattered, and transmitted by both medium breast tumor and nanoparticle. Penne's equation remains the same only the term of heat generation can be added to it another including the heat generated by nanoparticles, it is assumed that heat generation due to scattering is minimal. Then equation (6) can be written as: (Jain et al., 2006).

$\rho c \frac{\partial T}{\partial t}=k \nabla^{2} T+\rho_{b} \omega_{b} c_{b}\left(T_{b}-T\right)+Q_{m t}+Q_{1}+Q_{\text {heater }}$

The specific absorption rate in the tumor can be expressed as $\mu_{a t}$ represents total absorption by tumor $\mu_{a \text { tumor }}$ and nanoparticles $\mu_{\mathrm{aNp}}$ for scattering can be expressed by same method in which $\mu_{\text {st }}$ represents total scattering by tumor $\mu_{\text {stumor }}$ and nanoparticles $\mu_{\text {s NP }}$ (Aliannezhadi et al., 2018):

$$
\begin{aligned}
& \mu_{\mathrm{st}}=\mu_{\mathrm{s}} \text { tumor }+\mu_{\mathrm{sNP}} \\
& \mu_{\mathrm{at}}=\mu_{\mathrm{a} \text { tumor }}+\mu_{\mathrm{aNP}}
\end{aligned}
$$

Both equations (7) and (8) instituted in equation (1) to represent heat generated by laser source in photo thermal effect in tumor includes nanoparticles; this nanoparticles acts as nano heater in tumor, so heat generation by nanoparticles depend on the number of nanoparticles in tumor.

$$
\mathrm{Q}_{1}+\mathrm{Q}_{\text {heater }}=\mu_{\mathrm{at}}\left(\frac{\mathrm{p}_{1}}{\pi \mathrm{r}_{1}^{2}}\right) * \exp \left[-\left(\mu_{\mathrm{at}}+\mu_{\mathrm{st}}\right) * z^{*}\left(\frac{\mathrm{r}}{\mathrm{r}_{1}}\right)^{2}\right] \text { (9) }
$$

It is worth to mention that the absorption coefficient of breast tumor is differing from healthy tissue; both of them are function of wave length of incident laser beam (Qin and Bischof, 2012) (Carrillo-Cazares et al., 2017).

\section{MATERIALS AND METHODS}

The analysis of the cancer tissue model is performed using the Finite Element Method (FEM) to solve the bio-heat equation for the problem of heat transfer within the breast cancer tissues expressed in equation (9). Heat distributions within homogeneous tissue models are calculated using 
MATLAB in putting the thermal and biological parameters of the tissues listed in Tables 1 and 2, the type of tumor is non-invasive and it is located in the deep of the breast tissue, so contact with air is neglected using optical fibers to be very close to the center of the tumor represented by $z$ in equation (1). The tumor shape was regarded to be hemispherical with radius $r$, and the radius of the laser beam $r_{1}$ given that the tumor includes $\mathrm{N}$ is the number of Nano particles, which are irradiated by continuous laser beam $(\lambda$ $=797 \mathrm{~nm}$ ) appropriate with gold absorption.

As shown in Figure 1, the assumed cancer model was breast cancer tumor. Most of the actual tumors have a very complex geometry and inhomogeneous characteristics due to tissue variation between patients. However, in our numerical analysis has been considering both the complex geometry inhomogeneous characteristics of tumors and healthy tissue around the tumor. In this study, we select a simplified model compared to the actual breast cancer tumor.

The boundary conditions were considered to be symmetry; both the tumor and healthy tissue considered with the nearly the same temperatures: $\mathrm{T}_{\text {body }}=37^{\circ} \mathrm{C}$, the initial temperature of tissues was set as $35^{\circ} \mathrm{C}$ in our numerical

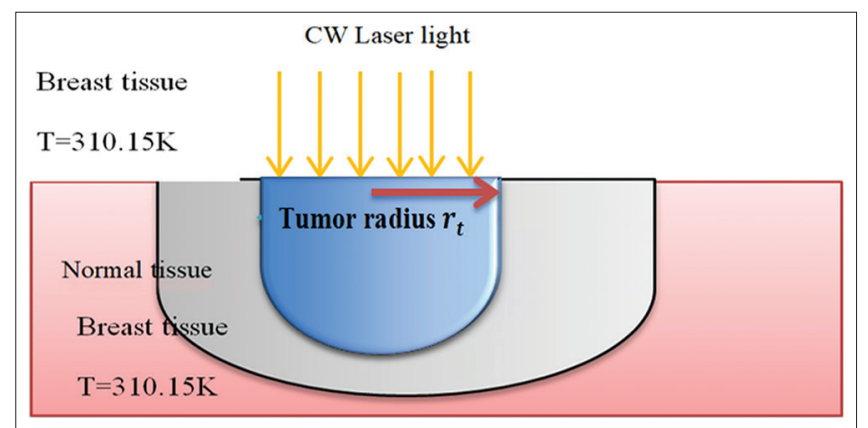

Figure 1: A schematic representation of the geometry for numerical analysis analysis, we evaluated the thermal and optical properties of AuNPs and those of the skin.

We have used two types of AuNPs, Gold Nano rods, and gold Nano sphere for our analysis. We have utilized two lasers 797 and $528 \mathrm{~nm}$ as the wavelength of the laser light, because this is the wavelength at gold Nano rods has maximum absorption, and $528 \mathrm{~nm}$ as the wavelength of the light source applied for gold Nano spherical. When Gold Nano rods are injected to the tumor, the thermal properties of the breast tumor may change, but changes in the thermal properties of the AuNPs were not considered in this study. In this study, the laser power ( $\mathrm{p}_{\text {) }}$ of $100 \mathrm{~W}$. A continuous wave laser source with Gaussian distribution was used for cancer irradiation.

\section{RESULTS AND DISCUSSION}

The modified bio-heat equation was solved iteratively using the FEM; using parameters laser power, time, laser output power, number of nanoparticle, type of nanoparticles, heat diffusion in tumor according to distance, and their impact on the temperature distribution with in the breast tumor.

Figure 2 shows the distribution of temperature in the center of the tumor has a radius of $0.5 \mathrm{~cm}$ contains $10^{15}$ particles of the gold Nano rod with radius $20 \mathrm{~nm}$ irradiated with laser source radius is same to tumor radius $0.5 \mathrm{~cm}$, irradiated with laser light output power of $\mathrm{p}_{1}=100 \mathrm{~W}$, which is far from the tumor about $0.001 \mathrm{~cm}$, during $2 \mathrm{~s}$ irradiated the tumor with absorption coefficient $\mu_{\mathrm{a}}$ tumor $=7(1 / \mathrm{m})$, the maximum temperature is about $319 \mathrm{~K}$ near the center of tumor which is equivalent to $45^{\circ} \mathrm{C}$, at the edge $0.57 \mathrm{~cm}$ from the middle of the tumor is close to the healthy tissue temperature of $310.15 \mathrm{k}$, equivalent to $37^{\circ} \mathrm{C}$.

Table 2: Properties of normal living tissue and breast tumor tissues (Hossain et al., 2016), (Kim et al., 2019)

\begin{tabular}{|c|c|c|c|}
\hline Description & Properties & Constant & Value \\
\hline \multirow[t]{5}{*}{ Normal tissue } & Density & $\rho\left(\mathrm{kg} / \mathrm{m}^{3}\right)$ & 1000 \\
\hline & Specific heat & $c_{p, n}(J / k g ~ k)$ & 4200 \\
\hline & Thermal conductivity & $\mathrm{k}_{\mathrm{n}}(\mathrm{W} /(\mathrm{m} \mathrm{K}))$ & 0.5 \\
\hline & Blood perfusion & $\mathrm{W}_{\mathrm{b}, \mathrm{n}}\left(\mathrm{m}^{3} / \mathrm{kg} / \mathrm{s}\right)$ & $1 \times 10^{-3}$ \\
\hline & Absorption coeffcient & $\mu_{a, n}(1 / m)$ & 2 \\
\hline \multirow[t]{5}{*}{ Tumor tissue with AuNPs } & Density & $\rho_{\mathrm{t}}\left(\mathrm{kg} / \mathrm{m}^{3}\right)$ & 1100 \\
\hline & Specific heat & $\mathrm{C}_{\mathrm{p}, \mathrm{t}}(\mathrm{J} / \mathrm{kg} \mathrm{K})$ & 4200 \\
\hline & Thermal conductivity & $\mathrm{k}_{\mathrm{t}}(\mathrm{W} /(\mathrm{m} \cdot \mathrm{K}))$ & 0.55 \\
\hline & Blood perfusion & $w_{b, t}\left(m^{3} / k g / s\right)$ & $6 \times 10^{-3}$ \\
\hline & Absorption coeffcient at $\lambda=797 \mathrm{~nm}$ at $\lambda=528 \mathrm{~nm}$ & $\mu_{-}(\mathrm{a}, \mathrm{t})(1 / \mathrm{m})$ & 712.1 \\
\hline \multirow[t]{4}{*}{ Other properties } & Blood density & $\rho_{\mathrm{b}}\left(\mathrm{kg} / \mathrm{m}^{3}\right)$ & 1000 \\
\hline & Blood specific heat & $\mathrm{C}_{\mathrm{p}, \mathrm{b}}(\mathrm{J} /(\mathrm{kg} \cdot \mathrm{K}))$ & 4000 \\
\hline & Metabolic heat & $Q_{m}\left(w / m^{3}\right)$ & 4200 \\
\hline & Artier blood temperature & $\mathrm{T}_{\mathrm{b}}(\mathrm{K})$ & 310.15 \\
\hline
\end{tabular}


Figures 3 and 4 explain the diffusion of heat in tumor of radius $0.5 \mathrm{~cm}$ including different AuNPs separately, with the same number $10^{15}$ of nanoparticles, both irradiated with same laser source with same properties, in center of both tumor the temperature is nearly same but the distribution of heat in tumor is different from each other, also around the tumor in the edge of tumor.

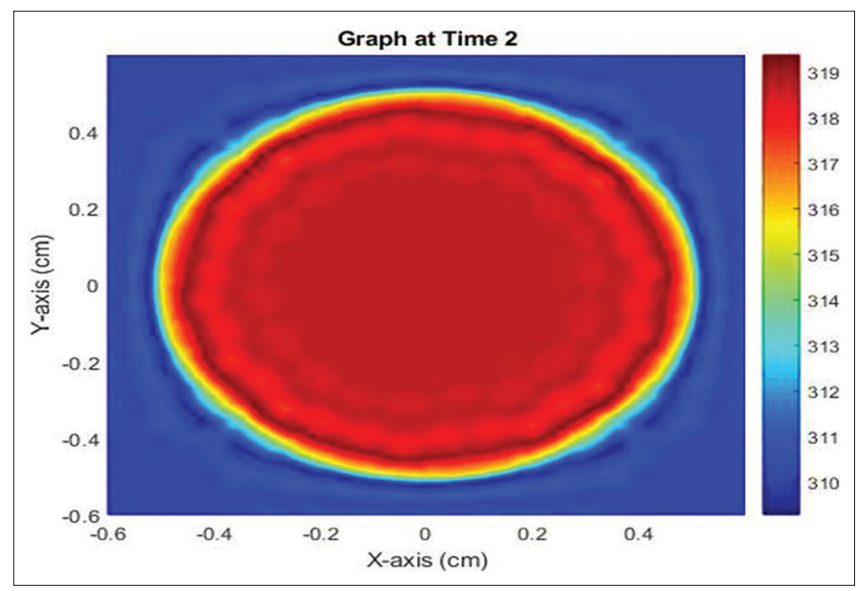

Figure 2: Characterizes of two dimensions $X Y$ heat diffusion with distance irradiated during $2 \mathrm{~s}$

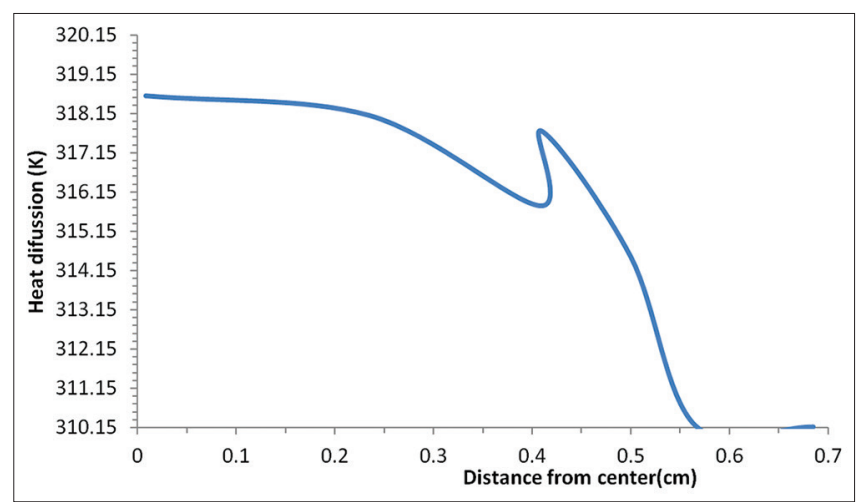

Figure 3: Temperature distribution with distance for tumor with Rod Gold nanoparticles irradiated during 2 s

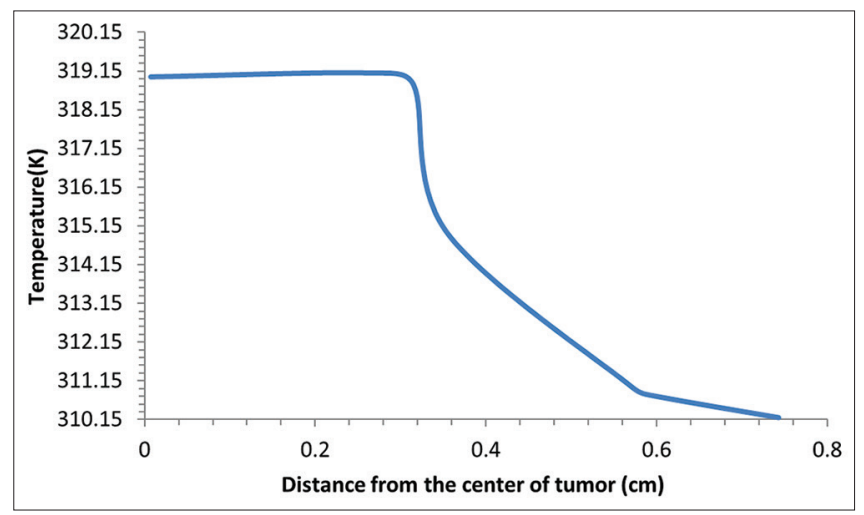

Figure 4: Temperature profile around tumor with Spherical gold nanoparticles irradiated during $2 \mathrm{~s}$
In Figure 5, tumor of radius $0.5 \mathrm{~cm}$ including $10^{15}$ of rod AuNPs and irradiated with same laser source, during $10^{-3} \mathrm{~s}$, the relationship between the powers of laser source with temperature at the center of tumor with increasing power of laser source from $10^{3}$ to $10^{4} \mathrm{~W}$ introducing heat from $311 \mathrm{~K}$ to $322 \mathrm{~K}$.

Figure 6 explains the relationship between the number of Rod AuNPs and the heat generation in tumor of radius $0.5 \mathrm{~cm}$, when irradiated with laser beam of $100 \mathrm{~W}$ with same radius of tumor $0.5 \mathrm{~cm}$ during $2 \mathrm{~s}$ for a generation of heat in the range of hyperthermia in breast tumor by increasing number of Rod GNPs from $10^{9}$ to $10^{16}$ nanoparticles the temperature increased from $316 \mathrm{~K}$ to $360 \mathrm{~K}$.

The optical property of normal tissue is different from tumor tissue then penetration depth is also different from each other. Penetration depth is reciprocal to attenuation coefficient. Figure 7 represents the relation of penetration of two type of medium breast tumor and normal tissue as function of wave length in normal tissue has maximum penetration at wave length $800 \mathrm{~nm}$ that is about $142.8 \mathrm{~mm}$ but breast tumor has maximum penetration depth at wave length $810 \mathrm{~nm}$ that is about $322.58 \mathrm{~mm}$. This result is

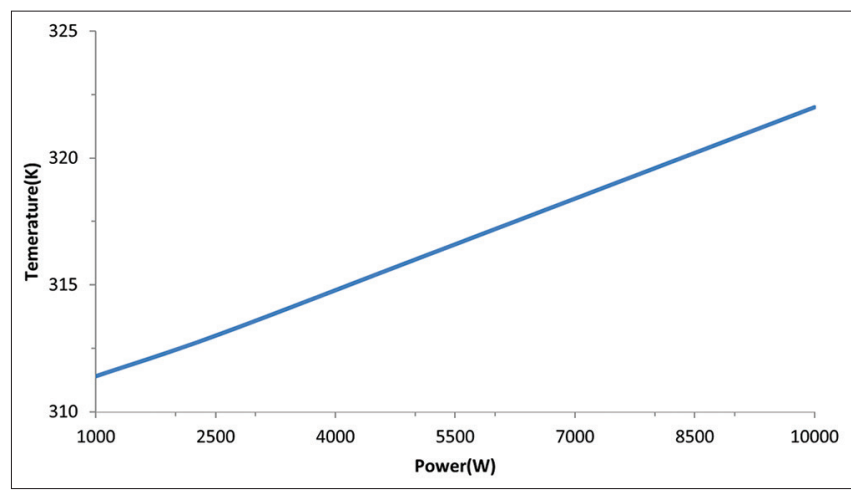

Figure 5: Temperature at the center of tumor including Rod AuNPs with change of laser power at exposer time $0.001 \mathrm{~s}$

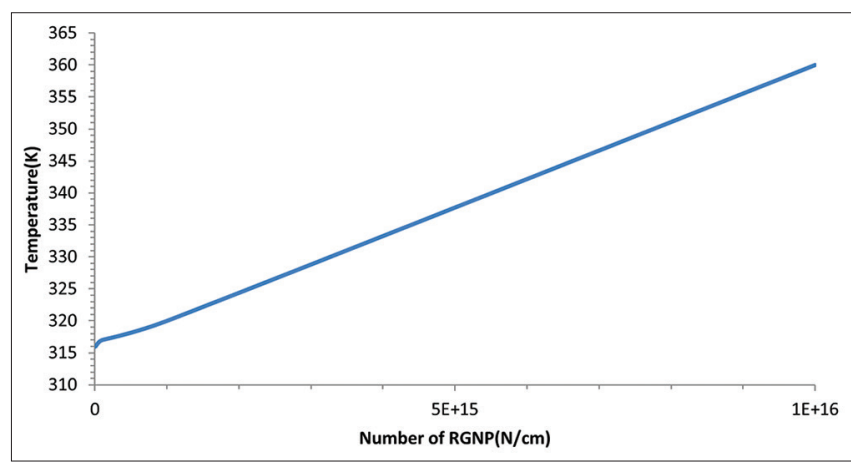

Figure 6: Relationship between number of Rod AuNPs and temperatures laser source irradiated breast tumor during $2 \mathrm{~s}$ 


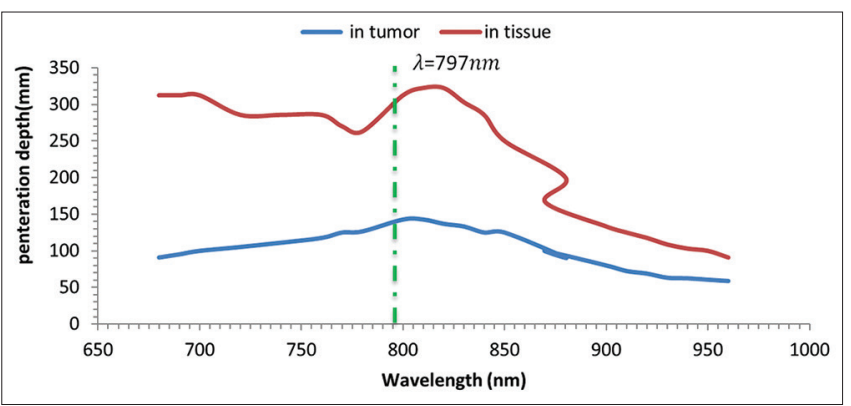

Figure 7: Penetration depth is represented as the function of the wave length to different medium healthy tissue and breast tumor

represent penetration depth in both type of tissue without including AuNPs.

Thermal damage normal tissues were predominantly influenced by the temperature of the tumor tissues. A high temperature in the center of tumor produced, when the high power of laser source is distributed over large area of tumor producing the heat in the range of hyperthermia temperature necrosis all the tumor with some thermal damage to normal tissue.

We used in this work FEM models to simulate the temperature distribution of the tumor. In the model constructed, parameters (laser power, number of Nano particles, type of AuNPs, and laser radius) are found to affect temperature distribution greatly.

If the time of irradiation of laser is reduced to $1 \mathrm{~ms}$ the heat generated is reduced, however increasing the power of continues laser source, the heat is generated is not increased it is prove of that hyper thermal with gold or without AuNPs effect in duration time smaller than millisecond.

In this study, we observed that for both type of AuNPs enhancing the heat generation in tumor if the number of particles is greater than $10^{8}$ particles in tumor the temperature is $316 \mathrm{~K}$ and is increased with increasing step by step the number of nanoparticles at $10^{16}$ particles in tumor the temperature in the center of tumor is $360 \mathrm{~K}$ and is the temperature in the range of hyperthermia.

The heat diffusion in tumor is studied for two different type of AuNPs rod and spherical both with same condition and irradiated with same laser condition but the distribution of temperature is differ from each other in tumor including Rod AuNPs the temperature is stable until $0.2 \mathrm{~cm}$ far from center of tumor. At the distance $0.45 \mathrm{~cm}$ far from the center of tumor the temperature rapidly increased after that peak the temperature reduced at the edge of tumor is close to the temperature of normal tissue $310 \mathrm{~K}$. There is almost the same result obtained in Miaskowski and Subramanian (Miaskowski and Subramanian 2019) a heat source in an experiment is magnetics power source the penne's heat equation modified with Robin's boundary condition to compute the temperature distribution within the breast phantom was investigated, the heat output raise to reach $316 \mathrm{~K}$ in whole tumor while $121 \mathrm{KW} / \mathrm{m}^{3}$ was required the temperature takes longer time about $500 \mathrm{~s}$ to reach the temperature in the range of hyperthermia degree (Miaskowski and Subramanian, 2019) while in penne's equation including AuNPs irradiated with laser source output power $100 \mathrm{~W}$ the temperature in the range of hyperthermia degree raises quickly. The heat rises rapidly with a specific time $2 \mathrm{~s}$.

In tumor tissue including spherical AuNPs the temperature is stable until the distance $0.4 \mathrm{~cm}$ from the center. It begins to skew and decreases the temperature with increasing distance from the center until reaches the edge $0.2 \mathrm{~cm}$ after the boundary of tumor the temperature is $311 \mathrm{~K}$ this area around the tumor is damaged nearly the same result of temperature distribution of tissue including AuNPs observed in Yakunin (Yakunin et al., 2015).

\section{CONCLUSIONS}

The induction of temperature profile in photothermal therapy is a significant factor, it can be concluded that the AuNPs in tumor enhanced the generation of heat in tumor and this enhancement of heat depend on the type and number of nanoparticles and the result is to necrosis or killing the tumor cells without killing the healthy cell of breast around of tumor, it mean the temperature at the edge of tumor be near the healthy tissue $310.15 \mathrm{~K}$.

This study investigated efficient treatment using photothermal therapy with NIR and Visible Continues Wave laser in terms of heat generation in center of tumor and heat diffusion to the surrounding normal tissue. However, using photothermal therapy can be accomplished when both clinical and theoretical studies of photothermal therapy are considered. Through further research, optimal treatment with photothermal therapy should be established.

The penetration depth of different wavelengths is estimated in the breast tumor and healthy tissue as a function of wave length, It was found, the normal tissue has maximum penetration at wave length $800 \mathrm{~nm}$ which is about 322.58 $\mathrm{mm}$, while for breast tumor is about $145 \mathrm{~mm}$ NIR wave length, this result helps physician for laser interaction with tissues particularly for diagnosis purpose, for example, the attenuation coefficient of tissue at wave length $500 \mathrm{~nm}$ is $12.1 \mathrm{~m}^{-1}$ then the penetration depth of light is $82.6 \mathrm{~mm}$ laser light penetrate the tumor and necrosis it, otherwise, it must use laser with fiber optics (Tromberg et al., 2000). 


\section{REFERENCES}

Abou Neel, E. A., L. Bozec, R. A. Perez, H. W. Kim and J. C. Knowles. 2015. Nanotechnology in dentistry: Prevention, diagnosis, and therapy. Int. J. Nanomed. 10: 6371-94.

Aliannezhadi, M., M. Minbashi and V. V. Tuchin. 2018. Effect of laser intensity and exposure time on photothermal therapy with nanoparticles heated by a 793-nm diode laser and tissue optical clearing. Quantum Electron. 48: 559.

Arora, D., M. Skliar and R. B. Roemer. 2002. Model-predictive control of hyperthermia treatments. IEEE Trans. Biomed. Eng. 49(7): 629-639.

Axelsson, P. 1999. Computer modelling of the temperature distribution in high intensity focused ultrasound thermotherapy. Lund Reports in Atomic Physics, Lund, Sweden.

Carrillo-Cazares, A., N. P. Jiménez-Mancilla, M. A. Luna-Gutiérrez, K. Isaac-Olivé and M. A. Camacho-López. 2017. Study of the optical properties of functionalized gold nanoparticles in different tissues and their correlation with the temperature increase. J. Nanomater. 2017: 3628970.

Collins, C., R. McCoy, B. Ackerson, G. Collins and C. Ackerson. 2014. Radiofrequency heating pathways for gold nanoparticles. Nanoscale. 6: 8459-8472.

Dahariya, S. and A. R. Betz. 2019. An Analytical Model to Determine the Maximum Allowable Point Source Heating with Minimal Risk to Phase-Change of Liquids in Brain Tissue. ASTFE Digital Library, Begel House Inc., Danbury.

Dykman, L. and N. Khlebtsov. 2011. Gold nanoparticles in biology and medicine: Recent advances and prospects. Acta Nat. 3: 34-55.

Hirsch, L. R., R. J. Stafford, J. A. Bankson, S. R. Sershen, B. Rivera, R. E. Price, J. D. Hazle, N. J. Halas and J. L. West. 2003. Nanoshell-mediated near-infrared thermal therapy of tumors under magnetic resonance guidance. Proc. Natl. Acad. Sci. 100(23): 13549-13554.

Hossain, S., M. Abdelaal and F. A. Mohammadi. 2016. Thermogram assessment for tumor parameter estimation considering body geometry. Can. J. Electr. Comput. Eng. 39: 219-234.

Hu, J., Z. Wang and J. Li. 2007. Gold nanoparticles with special shapes: Controlled synthesis, surface-enhanced Raman scattering, and the application in biodetection. Sensors (Basel). 7: 3299-3311.

Jain, P. K., K. S. Lee, I. H. El-Sayed and M. A. El-Sayed. 2006. Calculated absorption and scattering properties of gold nanoparticles of different size, shape, and composition: Applications in biological imaging and biomedicine. J. Phys. Chem. B. 110: 7238-7248.

Kim, M., G. Kim, D. Kim, J. Yoo, D. K. Kim and H. Kim. 2019.
Numerical study on effective conditions for the induction of apoptotic temperatures for various tumor aspect ratios using a single continuous-wave laser in photothermal therapy using gold nanorods. Cancers (Basel). 11: 764.

Lee, J., D. K. Chatterjee, M. H. Lee and S. Krishnan. 2014. Gold nanoparticles in breast cancer treatment: Promise and potential pitfalls. Cancer Lett. 347: 46-53.

Manuchehrabadi, N. and L. Zhu. 2017. Gold nanoparticle-based laser photothermal therapy. In: Handbook of Thermal Science and Engineering. Springer International Publishing, Switzerland. p1-33.

Miaskowski, A. and M. Subramanian. 2019. Numerical Model for magnetic fluid hyperthermia in a realistic breast phantom: Calorimetric calibration and treatment planning. Int. J. Mol. Sci. 20: 4644.

Niemz, M. H. 1996. Light and matter. In: Laser-Tissue Interactions. Springer, Berlin, Heidelberg. p9-43.

Peng, J. and X. Liang. 2019. Progress in research on gold nanoparticles in cancer management. Medicine (Baltimore). 98: e15311.

Pennes, H. H. 1948. Analysis of tissue and arterial blood temperatures in the resting human forearm. J. Appl. Physiol. 1: 93-122.

Qin, Z. and J. C. Bischof. 2012. Thermophysical and biological responses of gold nanoparticle laser heating. Chem. Soc. Rev. 41: 1191-1217.

Raji, V., J. Kumar, C. Rejiya, M. Vibin, V. N. Shenoi and A. Abraham. 2011. Selective photothermal efficiency of citrate capped gold nanoparticles for destruction of cancer cells. Exp. Cell Res. 317: 2052-2058.

Schena, E., P. Saccomandi and Y. Fong. 2017. Laser ablation for cancer: Past, present and future. J. Funct. Biomater. 8: 19.

Thomas, G. and R. Isaacs. 2011. Basic principles of lasers. Anaesth. Intensive Care Med. 12: 574-577.

Tromberg, B. J., N. Shah, R. Lanning, A. Cerussi, J. Espinoza, T. Pham, L. Svaasand and J. Butler. 2000. Non-invasive in vivo characterization of breast tumors using photon migration spectroscopy. Neoplasia. 2: 26-40.

Tung, M. M., M. Trujillo, J. L. Molina, M. J. Rivera and E. J. Berjano. 2009. Modeling the heating of biological tissue based on the hyperbolic heat transfer equation. Math. Comput. Model. 50(56): 665-672.

Yakunin, A. N., Y. A. Avetisyan and V. V. Tuchin. 2015. Quantification of laser local hyperthermia induced by gold plasmonic nanoparticles. J. Biomed. Opt. 20: 051030.

Zhang, Z. 2015. Transient bioheat transfer analysis in biological tissues by fundamental-solution-based numerical methods. Mol. Cell. Biomech. 1: 31-53. 